\title{
Effect of Temperature and Accelerator on Gel Time and Compressive Strength of Resin Anchoring Agent
}

\author{
Xiaohu Liu $\mathbb{D}^{1},{ }^{1}$ Zhishu Yao $\mathbb{D}^{1},{ }^{1}$ Weipei Xue $\mathbb{D}^{1,2}$ and Xiang Li $\mathbb{D}^{1}$ \\ ${ }^{1}$ School of Civil Engineering and Architecture, Anhui University of Science and Technology, Huainan 232001, China \\ ${ }^{2}$ Post-Doctoral Research Station of Safety Science and Engineering, Anhui University of Science and Technology, Huainan 232001, \\ China
}

Correspondence should be addressed to Zhishu Yao; zsyao@aust.edu.cn

Received 26 May 2019; Revised 17 July 2019; Accepted 24 July 2019; Published 18 September 2019

Guest Editor: Hetang Wang

Copyright (C) 2019 Xiaohu Liu et al. This is an open access article distributed under the Creative Commons Attribution License, which permits unrestricted use, distribution, and reproduction in any medium, provided the original work is properly cited.

In this study, we examined the effects of different temperatures and accelerators on the gelation (gel) time and compressive strength of a Polyethylene Terephthalate (PET)-type unsaturated polyester resin anchorage agent. First, the formation temperature of $20-70^{\circ} \mathrm{C}$ was simulated using self-made test equipment. N,N-Dimethylaniline (DMA), N,N-dimethylp-toluidine (DMT), and hydroquinone were selected as accelerators to determine gel time and heat release peak. The gel time of an anchorage agent is strongly influenced by accelerant and temperature. When DMT, DMA, and hydroquinone were added at the same temperature, the gelation time increased; with increasing ambient temperature, the gelation time of the anchorage agent decreased. The peak exothermic value of the curing reaction was less affected by the accelerator, and the peak exothermic value of the anchoring agent increased with the increase in ambient temperature. Then, the compressive strength of the anchorage agent, maintained at 20,50 , and $80^{\circ} \mathrm{C}$ for 1.5 , 6,12 , and $24 \mathrm{~h}$, was measured. We found that the compressive strength of resin anchorage agent decreased significantly with the increase in temperature, and the addition of DMT can improve the compressive strength of resin anchorage agent slightly at the same temperature conditions. Finally, through Fourier transform infrared scanning analysis, we determined the intrinsic causes of the influence of temperature and accelerator on the gelation time and compressive strength of the anchorage agent. Through SPSS fitting analysis, an empirical formula for predicting gelation time based on ambient temperature is proposed. Our findings provide a basis for reasonable mixing time and support design optimization of anchorage support in deep stratum in high-temperature geothermal environments.

\section{Introduction}

In mine roadways, bolt support is used for timely and active load bearing, which can significantly improve the self-supporting ability, and stability of the surrounding rock [1-3]. The resin anchorage agent is an important part of the bolt support system. These agents have the advantages of cure quickly at room temperature, high bonding strength, durability, and stability [4]. With increasing depths of coal mining, the average mining depth of most coal mines is about $650 \mathrm{~m}$, and the formation temperature is $35.9-36.8^{\circ} \mathrm{C}$. Some mines are now deeper than $1000 \mathrm{~m}$, and the formation temperatures can be as high as $40-50^{\circ} \mathrm{C}$. The spontaneous combustion of coal during coal mining also results in high-temperature geothermal environment [5-7]. The anchorage force on the bolt support system is often lower than the designed value due to the high-temperature geothermal environment in deep stratum, thereby reducing the anchorage safety [8-10].

The anchorage agent commonly used for bolt support in coal mine roadways is composed of unsaturated polyester resin, curing agent, accelerator, and filler. Under the action of a curing agent, unsaturated polyester resin and monomers copolymerize to form bulk thermosetting polymer, as exemplified in Figure 1 [11]. Typical formulations are as follows: 100 copies of unsaturated polyester resin, 5 copies of curing agent, 1 part of accelerator, and 500-550 copies of stone powder. According to construction site requirements, the general anchoring agents are divided into four types: ultrafast, fast, medium, and slow speed according to gel time. Generally, the gel time of resin anchorage agent is adjusted using accelerants and curing agents. 


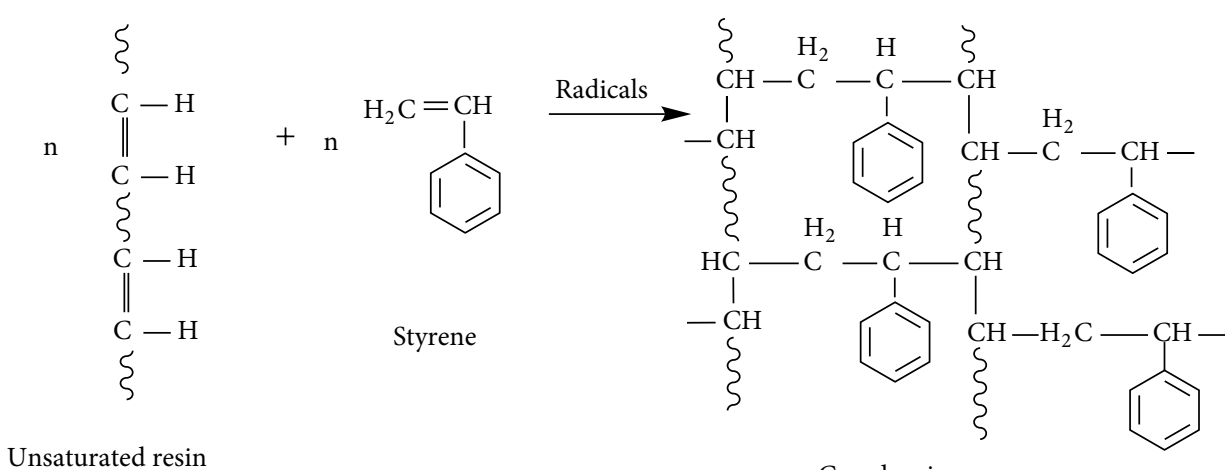

Cured resin

FIGURE 1: Anchoring agent curing reaction chemical equation.

According to China's MT 146.1-2011 standard [12], the gel time and mechanical properties of the anchorage agent are measured at $22 \pm 1^{\circ} \mathrm{C}$, and the high-temperature environment of deep mining is much higher than the standard temperature used when quantifying the properties of anchorage agents. Therefore, many scholars studied the influence of high-temperature geothermal environments on bolt support. Hu et al. [13] used the laboratory tests and numerical simulations to study the effect of temperature on the anchorage performance of resin bolts. Their conclusion was same as that obtained by Zhang et al. [14] at different temperatures: with increasing temperature, the anchorage force of resin bolt decreases. Wang et al. [15-16] studied the change in the gelation time of resin and resin anchorage agent at $-10-30^{\circ} \mathrm{C}$, finding that gelation time decreases significantly with increases in temperature. The maximum temperature studied was $30^{\circ} \mathrm{C}$, which is not suitable for guiding deep high-temperature bolt support. Nan et al. [17] studied the effects of curing temperature and curing agent type on the compressive strength, flexural strength, and elastic modulus of bisphenol F epoxy concrete. The high temperature at greater depths and accelerant types considerably influence the gel time and mechanical properties of resin anchorage agents. Determining an accurate cementing time of an anchorage agent is important for the reasonable arrangement of construction mixing and pallet installation time. The change in the mechanical properties of anchorage agents directly impacts the anchorage effect and has a greater impact on the reliability of bolt support in deep strata. Therefore, it is important to study the effects of temperature and accelerant on the gel time and mechanical properties of resin anchorage.

Taking the commonly used PET (Polyethylene Terephthalate)-type unsaturated polyester resin anchorage agent as the research object, we systematically studied the effect of different temperatures and accelerant types on the gel time, the peak value of heat release, and the compressive strength of the resin anchorage, and explored the changing mechanism through Fourier transform infrared (FTIR) scanning. SPSS regression analysis was used to analyze the function relationship between gel time $\left(t_{\text {gel }}\right)$ and environmental temperature $(t)$ of different types of anchorage agents to provide scientific basis for safe and effective anchorage support systems in deep earth strata in high-temperature environments.

\section{Materials}

2.1. Resin. Resin is one of the main components of anchorage agents. Unsaturated polyester resin is the least expensive and performs the best; therefore, it is widely used in the production of resin anchorage agents [18-20]. Among them, PET is a kind of unsaturated polyester resin, which has excellent mechanical properties, strong chemical stability, and low costs [21]. The chemical formula and properties of PET unsaturated polyester resin are shown in Figure 2 and Table 1.

2.2. Accelerator. In this study, two accelerators, N,Ndimethylaniline (DMA) and N,N-dimethylp-toluidine (DMT), were used to accelerate the gelation of the anchorage agent. Their molecular formulas are shown in Figures 3 and 4, respectively. By adjusting DMA and DMT, different cementing speeds of anchorage agent can be prepared at a standard temperature. According to experience, the total dosage of DMA and DMT is $1 \%$ of the resin quality [22]. To achieve slow cementing of the anchorage agent, hydroquinone is usually added to the resin as an inhibitor. The amount of hydroquinone is usually added according to the time of cementing. In this study, $0.04 \%$ of the resin quality was added to the anchorage agent [23].

2.3. Curing Agent. Unsaturated polyester resin is cured by radical-initiated polymerization, so it is necessary to use a redox initiator system. The curing agent (MeiYa Updated High-tech Material Industry Co., Ltd, Huainan, China) used in this study was a mixture of benzoyl peroxide (BPO), calcium carbonate, and ethylene glycol. The effective ingredient is benzoyl peroxide (BPO). Different contents of BPO change the gelling time of anchorage agent. In this experiment, a curing agent with $7 \%$ BPO content and $5 \%$ of the total weight of the anchoring agent cement was selected.

2.4. Aggregate. In this test, the aggregate (MeiYa Updated Hightech Material Industry Co., Ltd, Huainan, China) of the resin anchorage agent was stone powder, and the main composition and particle size distribution of stone powder were selected as shown in Tables 2 and 3, respectively. Because wet aggregates destroy the bonding force between the binder and aggregate and reduce the strength of the anchorage agent, the aggregate must be dried to a water content of $0.1 \%$ or less water [24]. 


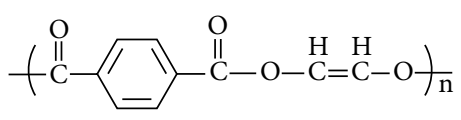

FiguRE 2: PET unsaturated polyester resin.

TABLE 1: Resin liquid index.

\begin{tabular}{lccc}
\hline Type & $\begin{array}{c}\text { Acid value } \\
(\mathrm{KOH} \mathrm{mg} / \mathrm{g})\end{array}$ & $\begin{array}{c}\text { Viscosity }\left(25^{\circ} \mathrm{C},\right. \\
\mathrm{mPa} . \mathrm{s})\end{array}$ & $\begin{array}{c}\text { Heat distortion } \\
\text { temperature }\left({ }^{\circ} \mathrm{C}\right)\end{array}$ \\
\hline PET & $10-20$ & $550-650$ & $50-55$ \\
\hline
\end{tabular}<smiles>CN(C)c1ccccc1</smiles>

Figure 3: N,N-Dimethylanilin (DMA).

\section{Experimental Campaign}

\subsection{Test Apparatus}

3.1.1. Anchorage Gel Time Test Facility. To determine the gel time of the anchorage agent in different formation temperature environments, it was necessary to create a constant temperature environment with different formation temperatures. In this study, we reformed the DHG-9145A blast drying box (Yiheng Scientific Instrument Co., Ltd, Shanghai, China) to create this environment. The DHG-9145A type blast dryer is manufactured according to Chinese national standard GB/T 10586-2006 [25]. Its temperature control range is room temperature (RT) $+10^{\circ} \mathrm{C}$ to $300^{\circ} \mathrm{C}$, and its constant temperature fluctuation is $\pm 1^{\circ} \mathrm{C}$. The door of the blast drying box was removed here. The soft insulation, made of $4 \mathrm{~mm}$ thick Polyvinyl chloride (PVC) soft crystal board (commonly known as soft glass) and $15 \mathrm{~mm}$ thick rubber-plastic sponge, was bonded to the opening of the blast drying box with epoxy resin and adhesive tape, as shown in Figure 5(a). The soft insulation door (Figure 5(b)) was divided into three layers. The first and third layers are PVC soft crystal plates with rubber sponges in the middle. The three layers were bonded by epoxy and then fixed by bolts. The physical drawings of the reformed blast drying box are shown in Figure 5. The result was the creation of a constant temperature environment for the cementing test of anchorage agents, which was tested with an electronic digital thermometer, stopwatch, and electronic balance. The experimenters wore gloves of long barrel cloth, and their hands were inserted through holes in the soft heat insulation.

3.1.2. Anchorage Compressive Strength Test Equipment. For the compressive strength test of the anchorage agent, we used a 101A-2 electric heating blast drying box to simulate the maintenance and growth of the anchorage agent in different temperature environments. We used a universal testing machine to conduct the compressive tests. Figures 6 and 7 show the universal testing machine and specimens for compressive strength test, respectively.<smiles>Cc1ccc(N(C)C)cc1</smiles>

FIgURE 4: N,N-Ddimethylp-toluidine (DMT).

TABLE 2: Main components of stone powder.

\begin{tabular}{lccccc}
\hline Component & $\mathrm{CaO}$ & $\mathrm{SiO}_{2}$ & $\mathrm{Al}_{2} \mathrm{O}_{3}$ & $\mathrm{MgO}$ & $\mathrm{Fe}_{2} \mathrm{O}_{3}$ \\
\hline Percentage (\%) & 57.7 & 25.9 & 5.6 & 2.5 & 0.6 \\
\hline
\end{tabular}

\subsection{Test Methods}

\subsubsection{Gel Time and the Peak of Heat Release Tests of Anchorage} Agent. The testing of the changing trend in the gel time of the resin anchorage under different temperatures and accelerators provides important reference information for reasonable mixing and tray installation time during the process of resin anchor installation. According to the Chinese coal industry standard MT146.1-2011 [12], the method used to measure the gel time of the resin anchorage agent is as follows: $100 \mathrm{~g}$ resin anchorage agent is placed in the center of the $150 \mathrm{~mm}$ polyester film; then the curing agent is fixed. Both are heated in a blast dryer for $20 \mathrm{~min}$ for the temperature to reach the test temperature and the test is verified using an electronic thermometer. Then, both hands are used to quickly and evenly mix the resin mortar and curing agent. Starting from the mixing resin paste, a stopwatch is used to record the gel time of the anchoring agent to the time when the cement thickens and the temperature begins to rise. The test block after the cementing of anchoring agent is shown in Figure 5(d). The measurement of the peak of heat release of resin anchorage agent was carried out after the gel time test and then the temperature of the test blocks was read to get its maximum value.

3.2.2. Compressive Strength Test of Anchorage Agent. In the full-length anchorage support system, the anchorage agent acts as the bond between the bolt and the rock mass, and its own strength affects the stability of the anchorage. According to China Coal Industry Standard MT146.1-2011 [12], compressive strength test method involves using standard die to make $40 \mathrm{~mm}$ cubic blocks in groups of three, as shown in Figure 7. After cementing, the test block is immediately removed from the mold and maintained in a $101 \mathrm{~A}-2$ electric heating blast drying box at different temperatures. The compressive strength test is conducted on the universal material testing machine. To control the temperature change of the test block to $\pm 3^{\circ} \mathrm{C}$, only one piece is removed in each test, and then the compressive strength test is conducted immediately. The temperature of the test piece is simultaneously measured using a F8380 type infrared thermometer [26].

3.2.3. Test Scheme. Four kinds of resin anchoring agent cements with different accelerator content were selected, and the resin anchoring agent cements were matched as shown in 
TABLE 3: Screening table for stone powder particles.

\begin{tabular}{lccccc}
\hline Type of stone powder & $10-50$ mesh & $50-100$ mesh & $100-150$ mesh & $150-200$ mesh & $200-325$ mesh \\
\hline Coarse (\%) & 95.1 & 2.53 & 1.83 & 0.48 & 0.06 \\
Fine (\%) & 10.7 & 17.2 & 10.6 & 44.1 & 17.4 \\
\hline
\end{tabular}

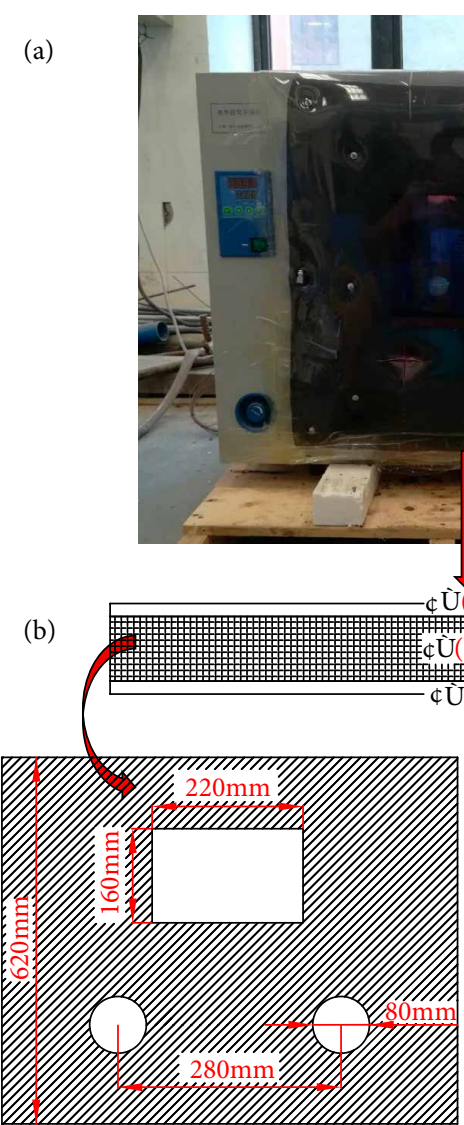

Rubber sponges
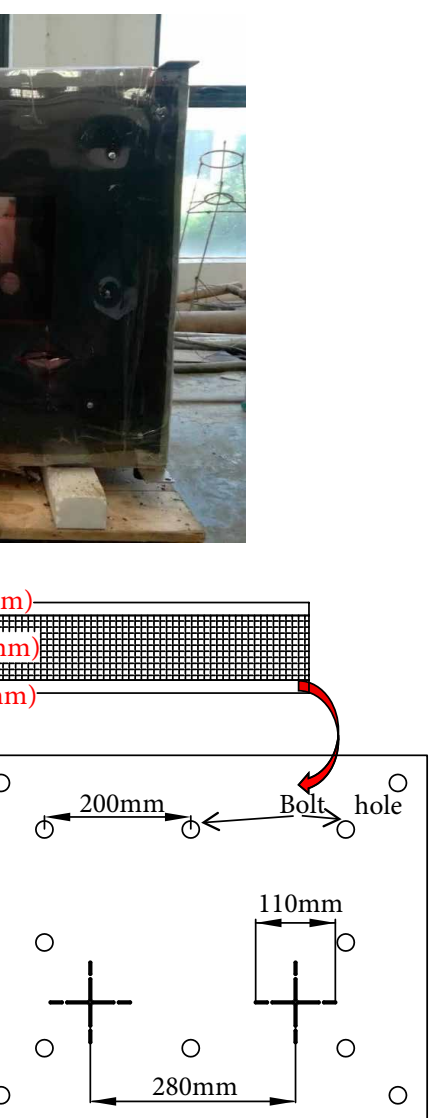

PVC soft crystal plates

(c)

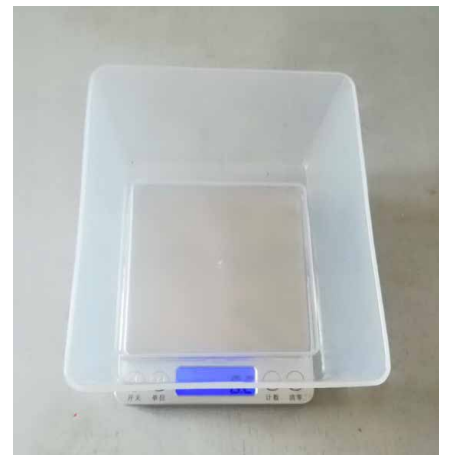

(d)

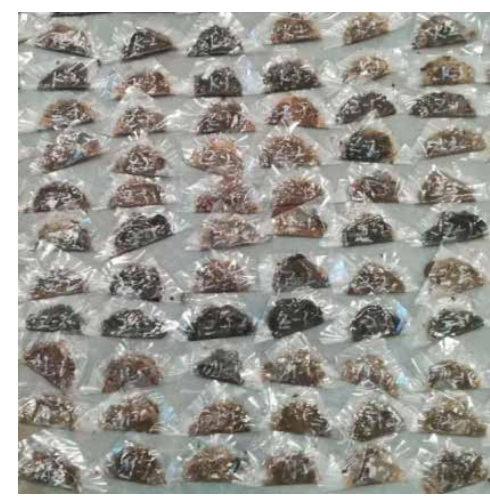

FIgURE 5: Gel time test device for resin anchorage agent. (a) The photo of blast drying oven after transformation, (b) soft insulation door sectional view, (c) electronic balance, and (d) anchoring agent gel time test sample.

Table 4 . In the test, the amount of curing agent was $5 \%$ of the quality of the resin anchoring agent cement. The gelation times of different types of resin anchorage were measured at 20,30, $40,50,60$, and $70^{\circ} \mathrm{C}$. Secondly, the compressive strength of the anchorage agent maintained at 20,50 , and $80^{\circ} \mathrm{C}$ for $1.5 \mathrm{~h}, 6 \mathrm{~h}$, $12 \mathrm{~h}$, and $24 \mathrm{~h}$ was measured. To reduce the accidental error in the two tests, each group of tests was conducted three times and the average value was recorded.

\section{Experimental Results and Analysis}

4.1. Effect of Temperature and Accelerant on Gelation Time of Resin Anchorage Agent. Figure 8 depicts the influence of different accelerators on the cementing time of anchorage agent at standard temperature $\left(20 \pm 1^{\circ} \mathrm{C}\right)$. For the A resin anchoring agent, we added $0.6 \%$ DMA and $0.4 \%$ DMT with
TABLE 4: Proportion table of resin anchorage cement.

\begin{tabular}{lcccccc}
\hline Type & PET & $\begin{array}{c}\text { Stone } \\
\text { power }\end{array}$ & $\begin{array}{c}\text { Curing } \\
\text { agent }\end{array}$ & DMA & DMT & $\begin{array}{c}\text { Hydro- } \\
\text { quinone }\end{array}$ \\
\hline A & 100 & 500 & 30 & 0.6 & 0.4 & 0 \\
B & 100 & 500 & 30 & 0.7 & 0.3 & 0 \\
C & 100 & 500 & 30 & 1 & 0 & 0 \\
D & 100 & 500 & 30 & 1 & 0 & 0.04 \\
\hline
\end{tabular}

resin quality, the gel time was $48.7 \mathrm{~s}$. We added $0.7 \%$ DMA and $0.3 \%$ DMT of the resin to the B-type resin anchorage, the gel time was $58.7 \mathrm{~s}$. For the C-type resin anchorage, we only added DMA. Compared with the A-type anchorage agent, with the decrease in the DMA content, the gel time of the B and C-type anchorage agents was $20.5 \%$ and $69 \%$, respectively. The adjustment of DMT content considerably affected the gel time change, whereas the amount of DMA had a relatively 


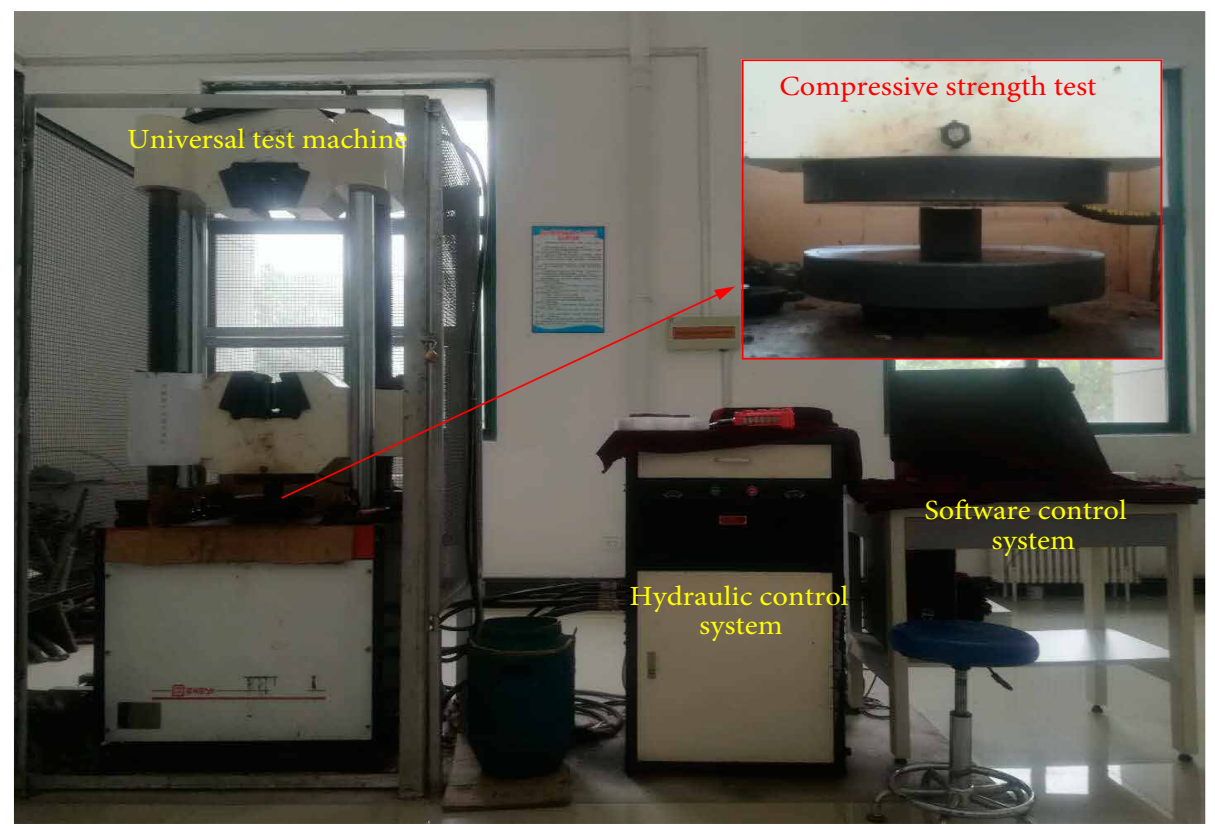

FIGURE 6: Diagram of compressive strength device used for testing the resin anchorage agent.

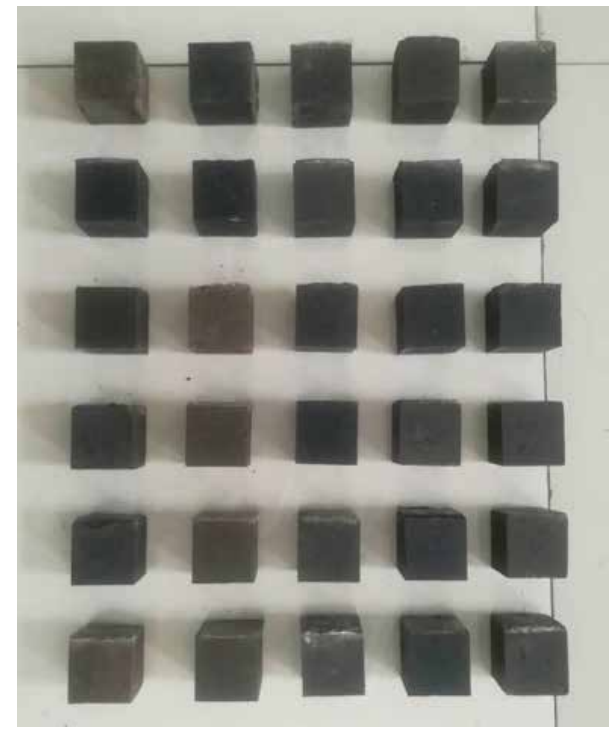

FIGURE 7: Specimens for compressive strength test.

stable effect on the gel time. By adding $0.03 \%$ inhibitor to D resin anchorage, the gel time increased to $605.6 \mathrm{~s}$. The addition of a micro inhibitor can greatly delay the gelation time. The cementing time of the anchorage agent can be adjusted by adding different accelerating doses to meet the different field construction technology requirements.

Figure 8 also shows the effect of different temperatures on the gel time of anchorage agent. As the temperature of the abscissa increases, the gel time of different types of resin anchorage decreases. The gelation times of the A-, B-, and C-type anchorage agents at $70^{\circ} \mathrm{C}$ were $11.7 \mathrm{~s}, 12.3 \mathrm{~s}$, and $16.6 \mathrm{~s}$, respectively, which is $76.0 \%, 79.0 \%$, and $81.6 \%$ lower than that

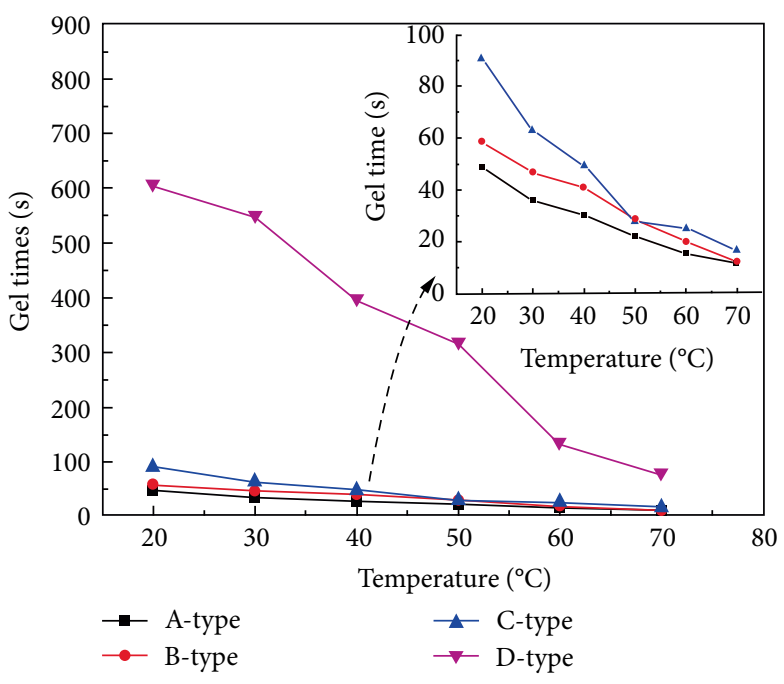

FIGURE 8: Gel time curve of resin anchorage at different temperatures.

at $20 \pm 1^{\circ} \mathrm{C}$, respectively. The $\mathrm{D}$-type anchorage agent is a slow anchorage agent. With the change in temperature, the gel time changes sharply. The gelation times were $547.6 \mathrm{~s}, 396.2 \mathrm{~s}$, $315.2 \mathrm{~s}$, and $132.9 \mathrm{~s}$ at temperatures of $30,40,50$, and $60^{\circ} \mathrm{C}$, respectively. The gelation time was $77.3 \mathrm{~s}$ at $70^{\circ} \mathrm{C}$, which is $87.2 \%$ lower than that at the standard temperature $\left(20 \pm 1{ }^{\circ} \mathrm{C}\right)$. As a kind of polymer, the gelling rate of resin anchorage agent is strongly influenced by temperature. Generally, the growth in polymer crystals depends on the speed of the diffusion and regular stacking of the segments toward the nucleus. With the increase in temperature, the viscosity of the polymer decreases, the activity of the segments increases, and the rate of crystal growth increases, so the gel rate increases [27]. 


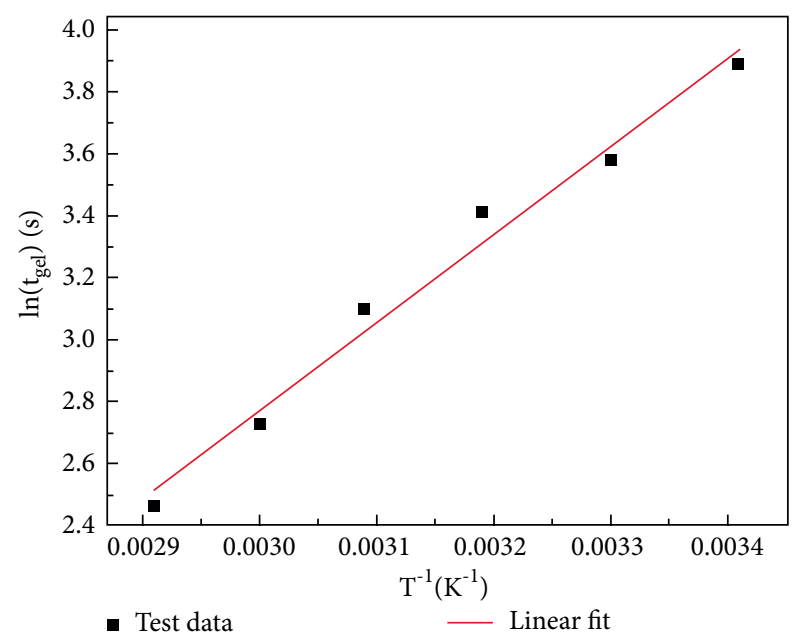

FIGURE 9: Arrhenius relationship of curing reaction of resin anchorage agent $\mathrm{A}$.

The gelation time of resin anchorage is dependent on the chemical reaction rate, and the rate of chemical reaction is related to the activation energy of the curing reaction. According to the Arrhenius equation, the relationship between gel time $\left(t_{\text {gel }}\right)$ and curing reaction activation energy $\left(E_{a}\right)$ is obtained [28]:

$$
\ln \left(t_{\mathrm{gel}}\right)=\frac{E_{a}}{R T}+B
$$

where $E_{a}$ is the activation energy of curing reaction, the molar gas constant $R$ is $8.3144 \mathrm{~J} /(\mathrm{mol} \cdot \mathrm{K})$, $T$ represents the thermodynamic temperature, $t_{\text {gel }}$ is the gel time, and $B$ is a constant term.

According to the experimental data of the anchorage gel time under different temperatures, a straight line about $\ln K$ $1 / T$ was obtained. The slope is the activation energy of the curing reaction. Taking the type A anchorage agent as an example, the Arrhenius relationship is shown in Figure 9.

The slope of the straight line in Figure 9 is 3026.566 . From equation (1), the activation energy of curing reaction of the type A resin anchorage agent was calculated to be $25.16 \mathrm{~kJ} /$ mol. Similarly, the activation energy of curing reaction of several other anchorage agents can be calculated, as shown in Table 5.

The inference from the integral equation of the Arrhenius equation is that in the same temperature range, the smaller the activation energy, the smaller the reaction rate. Therefore, the gel time of the anchorage agent is least affected by temperature. From Table 5, the activation energy of the curing reaction of A, B, C, and D anchorage increases gradually. The longer the gel time of an anchorage agent, the greater the temperature. Anchorage cementing is a kind of polymerization reaction. The reaction rate has a limit, so the effect of the anchorage temperature on the faster the cementing rate is relatively small. Generally, the type and temperature of the accelerator have a large influence on the gelling time of the anchorage agent. According to the specific technical requirements and the influence of temperature and environment at the construction site, a suitable type of anchorage agent should
TABLE 5: Activation energy of curing reaction for different types of resin anchors.

\begin{tabular}{lcccc}
\hline Resin type & A & B & C & D \\
\hline Activation energies $(\mathrm{kJ} / \mathrm{mol})$ & 25.16 & 29.19 & 31.50 & 43.02 \\
\hline
\end{tabular}

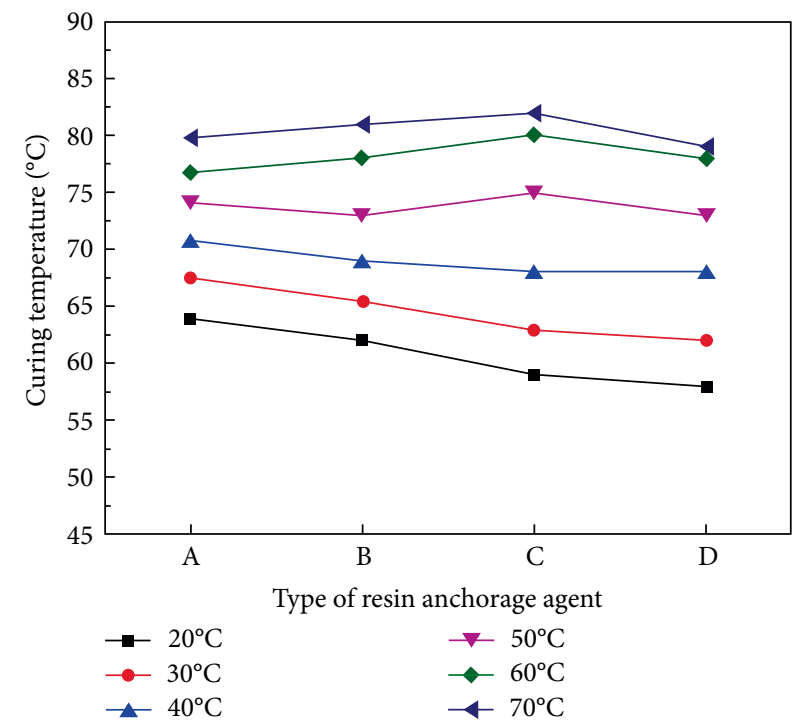

FIGURE 10: Peak curves of exothermic reaction.

be selected and the optimum mixing time of the anchorage agent should be determined.

\subsection{Influence of Temperature and Accelerant on the Peak of Heat} Release of the Resin Anchorage Gel. The exothermic peak is an important index in the polymer gelation reaction in addition to the gelation time. Figure 10 shows that the exothermic peak of different types of resin anchorage agent change little at the same temperature. Generally, the exothermic peak decreases slightly with increasing gelation time. Compared with type A, the exothermic peaks of the type $\mathrm{D}$ anchorage agent at $20^{\circ} \mathrm{C}$ and $30^{\circ} \mathrm{C}$ decreased by $9.38 \%$ and $8.28 \%$, respectively. With the increase in the ambient temperature, the exothermic peak temperatures of different types of anchorage agent increase and the differences in the exothermic peak temperatures between different types decrease gradually.

For the same resin anchorage agent, the exothermic peak temperatures vary greatly under different temperature environments. The thermal peak values of $\mathrm{A}, \mathrm{B}, \mathrm{C}$, and $\mathrm{D}$ resin anchorage agents increased by $24.69 \%, 30.65 \%, 38.98 \%$, and $36.21 \%$ at $70^{\circ} \mathrm{C}$, respectively. The curing exothermic peak of resin anchorage agent is less affected by the type of accelerator and more affected by environmental temperature.

\subsection{Effect of Temperature and Accelerator on the Compressive} Strength of Resin Anchor. The test results of the compressive strength at different temperatures are shown in Figure 11. At $20^{\circ} \mathrm{C}$, the compressive strength increases with the increase in curing time. Compared with the D-type anchorage agent, the A-, B-, and C-type anchorage agents have faster curing rates and faster increases in compressive strength. The 24-h 


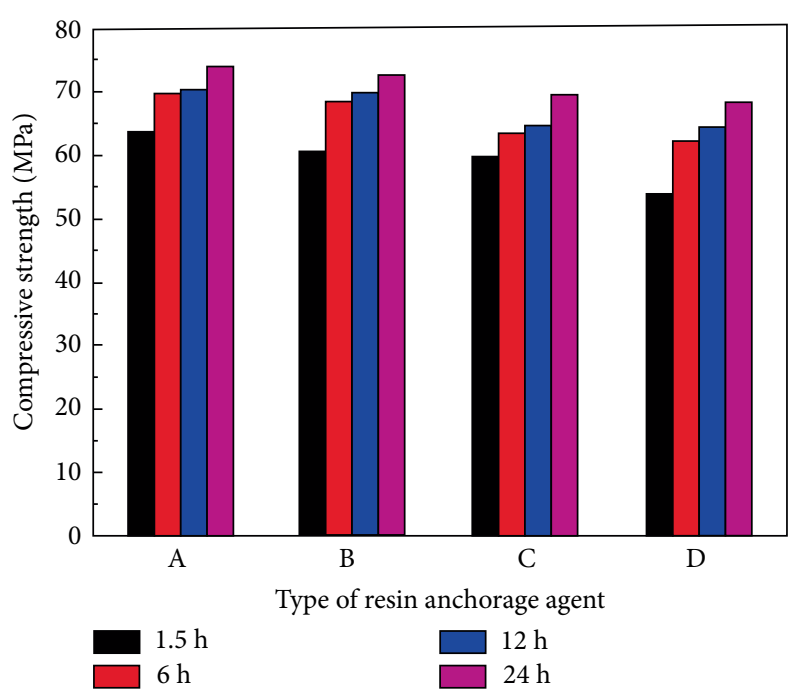

(a)

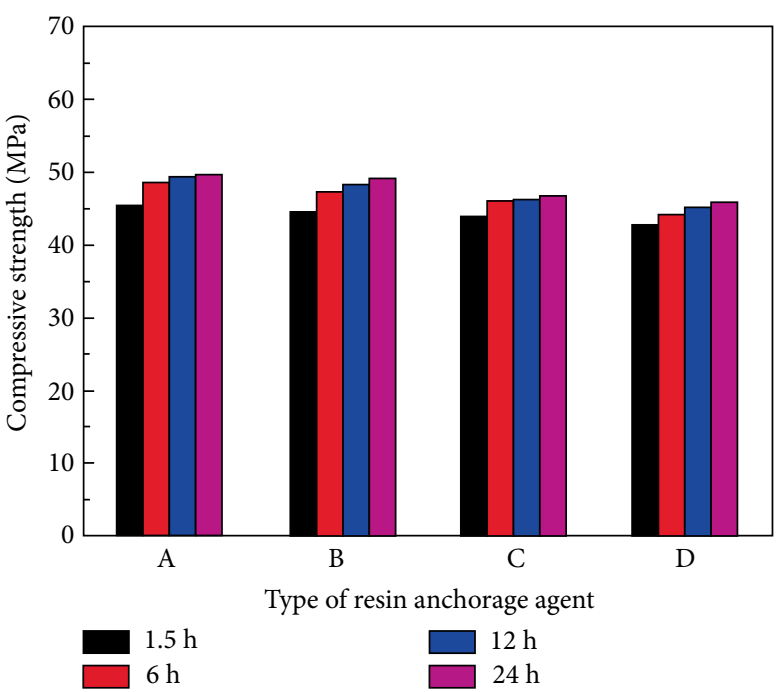

(b)

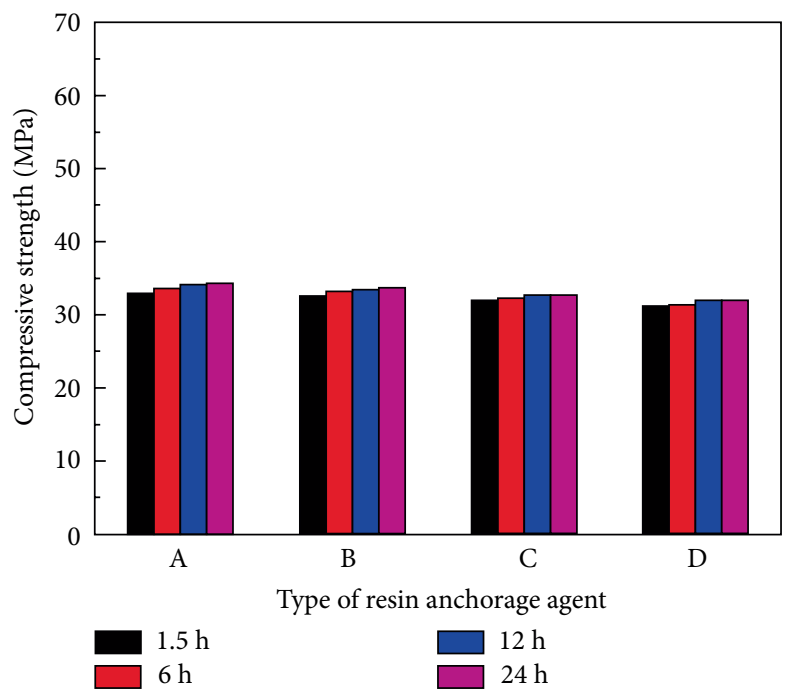

(c)

FIGURE 11: Column diagram of compressive strength of resin anchorage agent at different temperatures: (a) $20^{\circ} \mathrm{C}$, (b) $50^{\circ} \mathrm{C}$, and (c) $80^{\circ} \mathrm{C}$.

compressive strengths of A-, B-, C-, and D-type anchorage agents are $73.75 \mathrm{MPa}, 73 \mathrm{MPa}, 69.38 \mathrm{MPa}$, and $68.5 \mathrm{MPa}$, respectively. The compressive strength of the anchorage agent improved slightly by adding accelerator DMT. The compressive strength of the type A anchorage agent increased by $5.93 \%$ compared with type C, to which only DMA was added. With the increase in temperature, the influence of the accelerator on the compressive strength of the anchorage agent weakened at $50^{\circ} \mathrm{C}$ and $80^{\circ} \mathrm{C}$, and the growth rate of curing accelerated. In the $80^{\circ} \mathrm{C}$ environment, the anchorage agent reaches its maximum strength in 6-12 h. In addition, with the increase in temperature, the compressive strength of different types of resin anchorage agent decreased gradually. Taking the type A anchorage agent as an example, compared with $20^{\circ} \mathrm{C}$, the compressive strength of the anchorage agent decreased by $32.88 \%$ and $53.38 \%$ at $50^{\circ} \mathrm{C}$ and $80^{\circ} \mathrm{C}$, respectively. These results show that the effect of the accelerator on the compressive strength of the anchoring agent gradually decreases with the increase in the ambient temperature, and the overall impact is small. The ambient temperature strongly influences the compressive strength of the anchoring agent. Therefore, when designing the anchorage support for deep high-temperature mining roadways, the influence of the formation temperature on compressive strength should be considered, and the support parameters should be rationally optimized.

\section{FTIR Scanning Analysis}

The curing products of type $\mathrm{A}$ and $\mathrm{C}$ resin anchoring agents at $20^{\circ} \mathrm{C}, 40^{\circ} \mathrm{C}, 60^{\circ} \mathrm{C}$, and $70^{\circ} \mathrm{C}$ were selected and analyzed using a Nicolet 460 infrared spectroscope (Nicolet Instrument Corporation Madison, WI, USA). The FTIR spectra of the reaction products are shown in Figure 12. The stretching vibrations of hydroxyl $\mathrm{O}-\mathrm{H}, \mathrm{C}-\mathrm{H}$ and carbonyl $\mathrm{C}=\mathrm{O}$ are at $3420 \mathrm{~cm}^{-1}, 2870^{-1}$, and $1790 \mathrm{~cm}^{-1}$, respectively, while the 


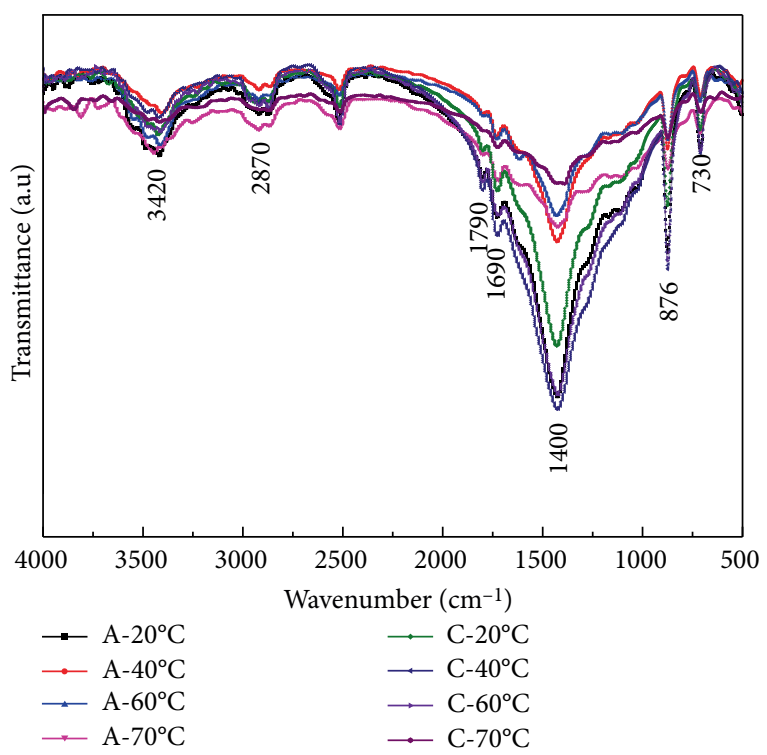

FIGURE 12: Fourier transform infrared (FTIR) scanning analysis of anchorage at different temperatures.

stretching vibration of the unsaturated double bond $\mathrm{C}=\mathrm{C}$ in polyester is at $1690 \mathrm{~cm}^{-1}$, and the peak at $1400 \mathrm{~cm}^{-1}$ can be ascribed to the symmetric stretching vibration of ethereal groups $\mathrm{C}-\mathrm{O}-\mathrm{C}$. The peaks at $876 \mathrm{~cm}^{-1}$ and $730 \mathrm{~cm}^{-1}$ are derived from $\mathrm{C}-\mathrm{H}$ group in benzene ring of $p$-phenyl-type [29].

Comparing the FTIR spectra of cured products of type A and $\mathrm{C}$, it can be seen that the functional groups of the products of resin anchorage polymerization under different temperatures and accelerators are the same, and no new functional groups are produced. The polymerization reaction occurs between the unsaturated polyester resin and styrene in the resin anchorage. With the increase in crosslinking degree of the polymer products, the number of $\mathrm{C}-\mathrm{H}$ on the saturated alkyl group at $2870 \mathrm{~cm}^{-1}$ in the polymer will increase. The ratio of the number of $\mathrm{C}-\mathrm{H}$ at $2870 \mathrm{~cm}^{-1}$ to that of ethereal group at $1400 \mathrm{~cm}^{-1}$ in type $\mathrm{A}$ anchorage agent is larger than that of type $\mathrm{C}$ anchorage agent. It can be seen that the crosslinking degree of cured products of type A anchorage agent is relatively high. Therefore, the addition of accelerator DMT increases both the curing rate and the degree of polymerization of resin anchorage agent. This conclusion reveals the intrinsic reason why the addition of DMT in the compressive strength test of resin anchorage agent can improve the compressive strength of anchorage agent by a small margin.

\section{Regression Analysis of Gel Time Law of Anchorage Agent}

To better guide field production practice, statistical analysis software SPSS (IBM, NY, USA) was used to complete the regression analysis on the gel time test data. Taking temperature as an independent variable, the functional relationship between gel time and the independent variables of the resin anchoring agent with different accelerant contents was determined. Gelation time of the anchorage of different types of
TABLE 6: Gelation time of the anchorage of different types of resin in different temperature environments.

\begin{tabular}{lcccc}
\hline Environment temperature $\left({ }^{\circ} \mathrm{C}\right)$ & $\mathrm{A}(\mathrm{s})$ & $\mathrm{B}(\mathrm{s})$ & $\mathrm{C}(\mathrm{s})$ & $\mathrm{D}(\mathrm{s})$ \\
\hline 20 & 48.7 & 58.7 & 90.3 & 605.6 \\
30 & 35.7 & 46.8 & 62.9 & 547.6 \\
40 & 30.2 & 41.1 & 49.2 & 396.2 \\
50 & 22.1 & 28.7 & 27.8 & 315.2 \\
60 & 15.3 & 20.1 & 25.0 & 132.9 \\
70 & 11.7 & 12.3 & 16.6 & 77.3 \\
\hline
\end{tabular}

resin in different temperature environments in the testing results is as shown in Table 6 .

From Table 6, it can be seen that different types of resin anchorage agents have different change rates of gelation time at different temperatures. As shown in Figure 13, by comparing linear function, logarithmic function, exponential function, power function, and quadratic polynomial of curve fitting coefficient, the quadratic polynomial was used to describe the relationship between gelation time and temperature of resin anchoring agent.

The functional relations between gel time $\left(t_{\mathrm{gel}}\right)$ and temperature $(t)$ of A, B, C, and D types were shown in (2), (3), (4), and (5), respectively.

$$
\begin{aligned}
& \text { A type }: t_{\text {gel }}=72.917-1.398 t+0.007 t^{2} \\
& \text { B type }: t_{\text {gel }}=79.093-1.07 t+0.002 t^{2} \\
& \text { C type }: t_{\text {gel }}=152.949-3.666 t+0.025 t^{2} \\
& \text { D type }: t_{\text {gel }}=821.249-0.954 t-0.02 t^{2}
\end{aligned}
$$

Through the above research, we found that the gel time of the resin anchorage agent can be calculated under known formation temperature, and a reasonable mixing time and time of pallet installation can be determined for use during the construction of the anchoring process to avoid excessive agitation in anchorage support to reduce anchorage force. The testing confirmed that the compressive strength of the anchorage agent itself decreases with the increase in ambient temperature, and the ultimate bearing capacity of the anchorage agent usually decreases. To improve the reliability of the bolt support system in high-temperature geothermal environment, the strength of bolt support is usually increased by increasing the length and support density of the bolt support [30]. However, when the local temperature of the anchorage agent is too high, the compressive strength of the PET resin anchorage agent decreases too much, which could easily cause support failure. Given this situation, we developed a new type of anchorage agent, anchorage agent $\mathrm{l}$, based on the existing PET anchorage agent mixed with FX-470 resin to modify the mixing of PET and KH-570, and obtained a resin anchorage agent with high strength and excellent heat resistance to solve the problem of anchorage loss in high-temperature ground [31]. 


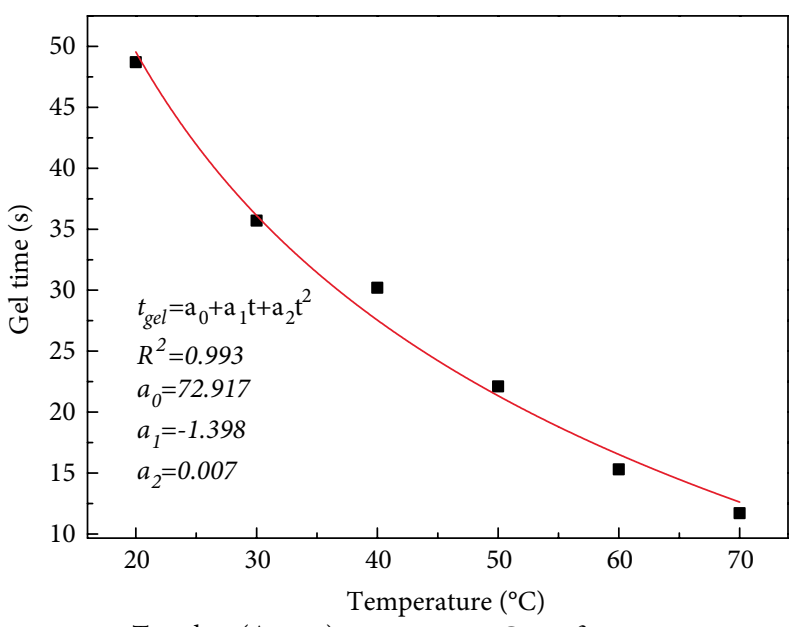

- Test data (A-type) — Curve fitting

(a)

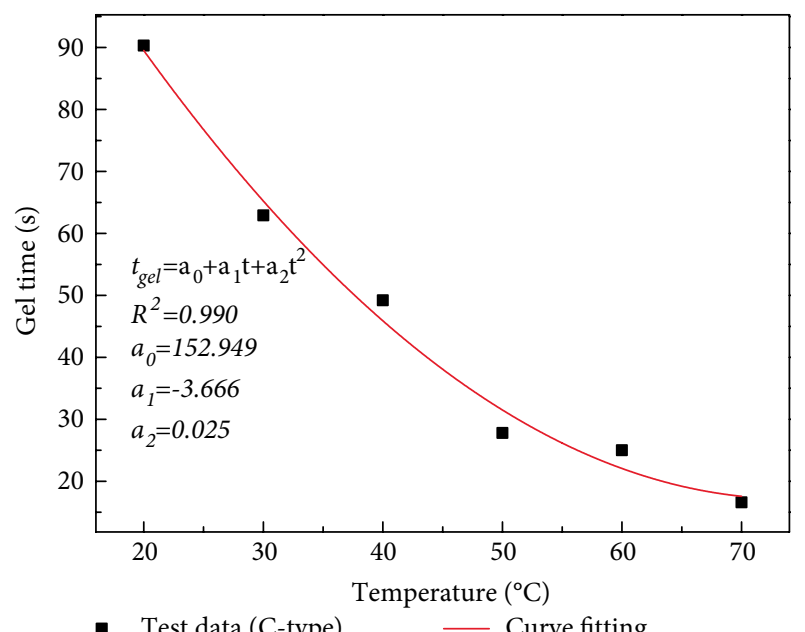

- Test data (C-type) — Curve fitting

(c)

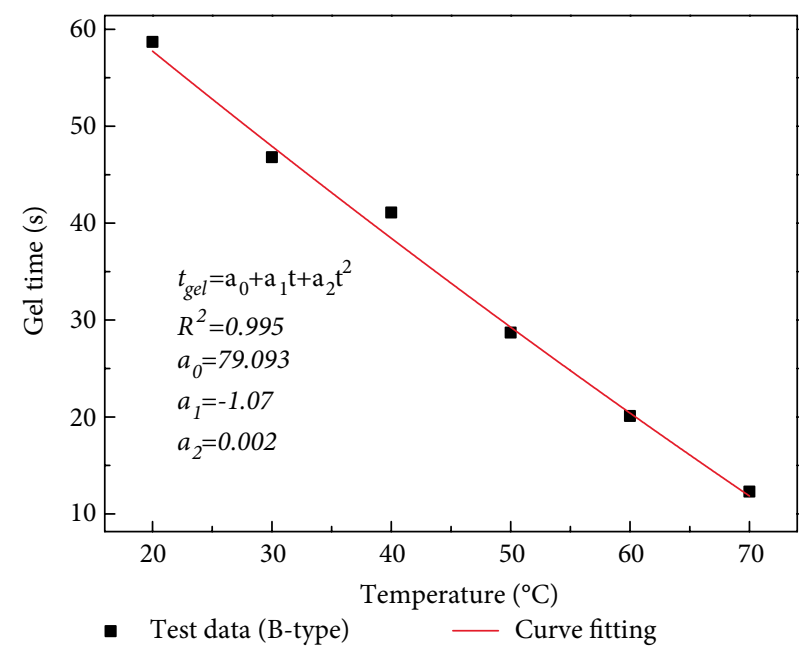

(b)

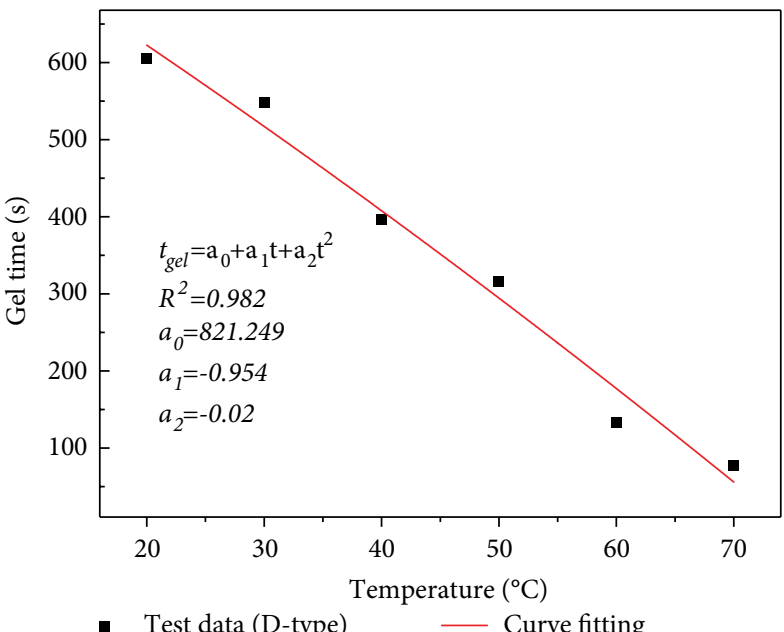

(d)

FIGURE 13: The regression function curve of the relationship between gelation time and temperature: (a) A-type, (b) B-type, (c) C-type, and (d) D-type.

\section{Conclusions}

The effects of different temperatures and accelerators on gelation time and compressive strength of PET resin anchorage were studied. The results are summarized as follows:

(1) Through the cementing time test of the anchorage agents, we found that the accelerator DMT is more active than DMA, and the trace hydroquinone inhibitor has a strong influence on the gel time. The environmental temperature of $20-70^{\circ} \mathrm{C}$ was simulated using a designed test chamber, and the gelation time of the anchorage decreased with the increase in ambient temperature. According to the gel time and environmental temperature test data, the activation energies of curing reactions of the A-D anchorages were deduced to be $25.16 \mathrm{~kJ} / \mathrm{mol}, 29.19 \mathrm{~kJ} / \mathrm{mol}$, $31.50 \mathrm{~kJ} / \mathrm{mol}$, and $43.02 \mathrm{~kJ} / \mathrm{mol}$, respectively.
(2) Different accelerators have little effect on the peak value of the heat release of the resin anchorage. The faster the gel speed at the same temperature, the greater the exothermic peak. With the increase in ambient temperature, the peak value of the curing heat release for all kinds of resin anchorage increases. The curing products of the anchorage agent at different temperatures and accelerators were analyzed by FTIR scanning, and the internal causes of the changes in gelation time and exothermic peak value were revealed at the micro level.

(3) Compressive strength tests under different temperature environments showed that the type of accelerator has little influence on the compressive strength of the anchorage agent. Compared with the C-type anchorage agent, the compressive strength of the A-type anchorage agent increases by $5.93 \%$ when adding DMT, whereas the temperature change has a 
greater impact on the compressive strength of anchorage agent, which decreased by $35.36 \%$ and $50.14 \%$ at $50^{\circ} \mathrm{C}$ and $80^{\circ} \mathrm{C}$, respectively.

(4) Regression analysis based on the experimental data of the gel time and temperatures of different types of resin anchorages, completed using SPSS analysis software, showed that the relationship between gel time and ambient temperature obeys the quadratic polynomial function, providing a basis for determining reasonable mixing and tray installation time.

\section{Data Availability}

The data used to support the findings of this study are available from the corresponding author upon request.

\section{Conflicts of Interest}

The authors declare that they have no conflicts of interest.

\section{Authors' Contributions}

Conceptualization, Xiaohu Liu and Zhishu Yao; Formal analysis, Weipei Xue; Methodology, Xiaohu Liu; Resources, Xiang Li; Writing-original draft, Xiaohu Liu.

\section{Acknowledgments}

This research was supported by the National Natural Science Foundation of China (No. 51674006) and the Anhui University discipline professional talented person (No. gxbjZD09), Anhui Provincial Natural Science Foundation Youth Project (1908085QE185), Anhui Provincial College of Natural Science Research Key Project (KJ2018A0098), Project funded by China Postdoctoral Science Foundation (2018M642502), and the Science Research Foundation for Young Teachers in Anhui University of Science and Technology (QN2017211).

\section{References}

[1] H. Kang, "Sixty years development and prospects of rock bolting technology for underground coal mine roadways in China," Journal of China University of Mining \& Technology, vol. 45, no. 6, pp. 1071-1081, 2016.

[2] B. Navid and H. John, "Explicit reinforcement models for fully-grouted rebar rock bolts," Journal of Rock Mechanics and Geotechnical Engineering, vol. 9, no. 2, pp. 267-280, 2017.

[3] K. Zhang, G. Zhang, R. Hou, Y. Wu, and H. Zhou, "Stress evolution in roadway rock bolts during mining in a fully mechanized longwall face, and an evaluation of rock bolt support design," Rock Mechanics and Rock Engineering, vol. 48, no. 1, pp. 333-344, 2015.

[4] J.Y. Lv, "The appliance of resin anchor in mine," Waterpower Excavating Coal and Pipeline Transport, vol. 3, pp. 33-36, 1996.
[5] W. J. Yao and J. Y. Pang, "The status and progress of the research on thermal environment of deep mine in China," Mining Safety \& Environmental Protection, vol. 45, no. 1, pp. 107-111, 2018.

[6] H. Lan, D. K. Chen, and D. B. Mao, "Current status of deep mining and disaster prevention in China," Coal Science and Technology, vol. 44, no. 1, pp. 39-46, 2016.

[7] Y. Lu, "Laboratory study on the rising temperature of spontaneous combustion in coal stockpiles and a paste foam suppression technique," Energy \& Fuels, vol. 31, no. 7, pp. 7290-7298, 2017.

[8] S. Xue-gui, D. Xian-jie, Y. Hong-hu, and L. Ben-kui, "Research of the thermal stability of structure of resin anchoring material based on 3D CT," International Journal of Adhesion \& Adhesives, vol. 68, pp. 161-168, 2016.

[9] C. H. Kang, "Study on the influence of temperature on the mechanical properties of resin anchor," AnHui University of Science and Technology, 2017.

[10] Y. Lu, S. Shi, H. Wang, Z. Tian, Q. Ye, and H. Niu, “Thermal characteristics of cement microparticle-stabilized aqueous foam for sealing high-temperature mining fractures," International Journal of Heat and Mass Transfer, vol. 131, pp. 594-603, 2019.

[11] C. Y. Zheng and N. J. Huang, Resin Anchor and Anchoring Agent, China Coal Industry Publishing Home, 1983.

[12] China Standards Publication, Resin Anchor Bolts-Part 1: Capsules, MT 146.1-2011, Standard Press of China, Beijing China, 2011.

[13] B. Hu, H. P. Kang, J. Lin, J.-F. Cai, and P.-F. Jiang, "Study on influence of temperature on anchorage performance of resin anchored bolt," Journal of Mining \& Safety Engineering, vol. 29, no. 5, pp. 644-649, 2012.

[14] S. Zhang, P. F. Gou, and H. Fan, "Influence of water and temperature on resin anchor-hold," Journal of Southeast University (Natural Science Edition), vol. 35, no. 1, pp. 50-54, 2005.

[15] J.-Y. Wang, J.-M. Guo, J.-F. Mi, Y. Zhang, and A.-R Shi, "Influence of the temperature on the gel time of the capsules in rock bolting system," Journal of China Coal Society, vol. 33, no. 6, pp. 619-622, 2008.

[16] J.-Y. Wang, "Quantity of accelerant affected to gel time of anchoring agent for resin bolt," Coal Science and Technology, vol. 36, no. 11, pp. 23-25, 2008.

[17] J. J. Nan, Y. Jaeheum, S. Inbae, and Y. Kyu-Seok, "Effects of curing temperature and hardener type on the mechanical properties of bisphenol F-type epoxy resin concrete," Construction and Building Materials, vol. 156, pp. 933-943, 2017.

[18] Z. R. Wang, "Resin anchoring agent," Chemical Building Materials, vol. 1, pp. 24-27, 2001.

[19] S. M. Wang, Z. J. Zhu, and X. H. Lu, "Synthesis and application of unsaturated polyester resin for glycerol modified anchoring agent," China High-Tech, vol. 1, no. 4, pp. 14-16, 2017.

[20] J. Zhao, "Talking about the factors affecting the reduction of anchorage force of coal mine underground bolt," Scientific Management, vol. 10, pp. 260-261, 2017.

[21] Z. Y. Hu and S. M. Wang, "Systematic study on influencing factors of main performance indexes of resin anchoring agent," Science and Technology Economic Guide, vol. 19, pp. 78-79, 2017.

[22] X. H. Lu, "Development of quick repairing clay," Science and Technology Economic Guide, vol. 19, pp. 81-82, 2017. 
[23] F. F. Liu, X. H. Yuan, and Q. N. Feng, "Study on a curing system of unsaturated polyester resin," Fiber Reinforced Plastics/ Composites, vol. 3, pp. 70-73, 2015.

[24] O. Elalaoui, E. Ghorbel, V. Mignot, and O. M. Ben, "Mechanical and physical properties of epoxy polymer concrete after exposure to temperatures up to $250^{\circ} \mathrm{C}$," Construction and Building Materials, vol. 27, no. 1, pp. 415-424, 2012.

[25] China Standards Publication, Specification for Damp Heat test chambers, GB/T 10586-2006, Standard Press of China, Beijing, China, 2006.

[26] Y. Lu, S. Shi, F. Yang, T. Zhang, H. Niu, and T. Wang, "Mo-doping for improving the $\mathrm{ZrF}$ coated- $\mathrm{Li}\left[\mathrm{Li}_{0.20} \mathrm{Mn}_{0.54} \mathrm{Ni}_{0.13} \mathrm{Co}_{0.13}\right] \mathrm{O}_{2}$ as high performance cathode materials in lithium-ion batteries," Journal of Alloys and Compounds, vol. 767, pp. 23-33, 2018.

[27] N. Naofumi, M. Ryo, K. Shuntaro et al., "Synthesis of joint-linker type gels and porous polymers by addition reactions of multifunctional thiol and alkyl diacrylate, diisocyanate compounds," Materials Today Communications, vol. 18, pp. 153-162, 2019.

[28] D.-B. Guan, Z.-Y. Cai, X.-C. Liu et al., "Rheological study on the cure kinetics of two-component addition cured silicone rubber," Chinese Journal of Polymer Science, vol. 34, no. 10, pp. 1290-1300, 2016.

[29] J. X. Zhou and B. X. Dong, "A study on the infra-red spectrometry of unsaturated polyesters," Thermosetting Resin, vol. 18, no. 4, pp. 22-24, 2003.

[30] M. Zhao, "Study on impact of anchorage length on anchorage effect," China University of Mining and Technology, 2016.

[31] X. Liu, Z. Yao, W. Xue, and X. Li, "Development, performance, and microscopic analysis of new anchorage agent with heat resistance, high strength, and full length," Advances in Materials Science and Engineering, vol. 2019, Article ID 4239486, 9 pages, 2019. 


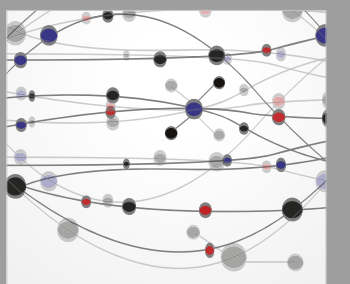

The Scientific World Journal
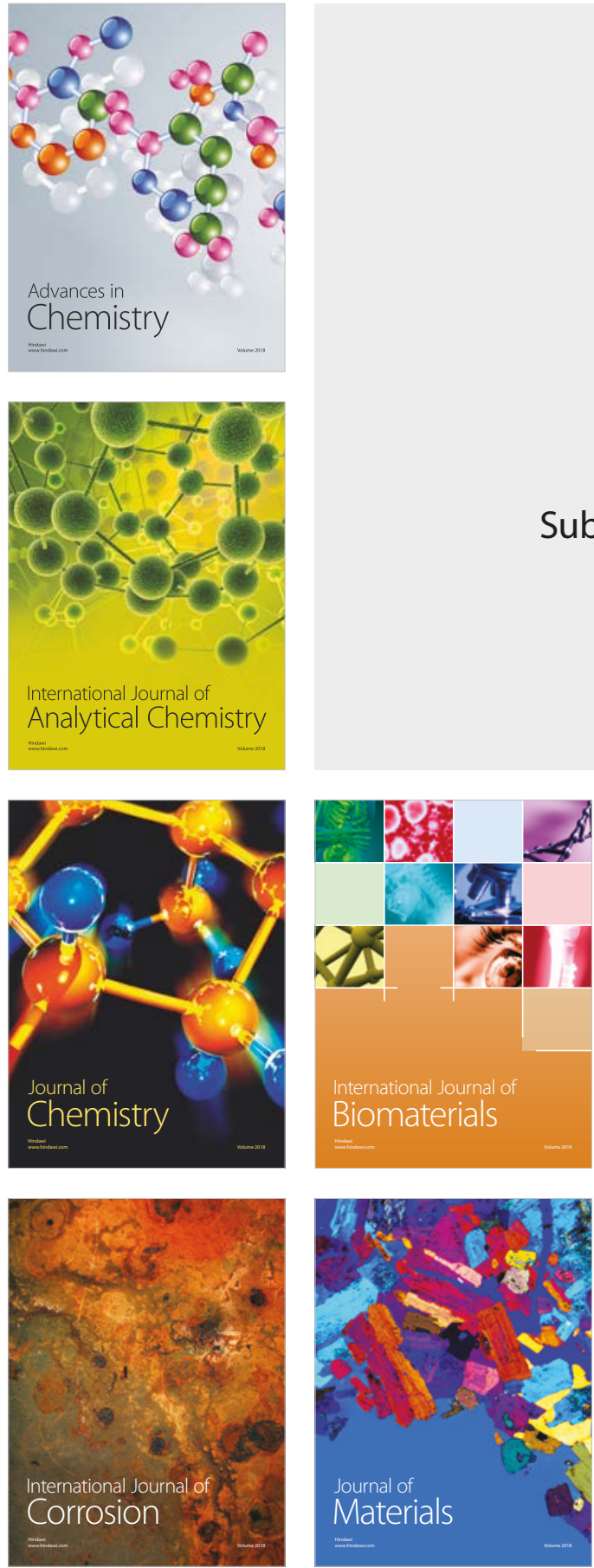

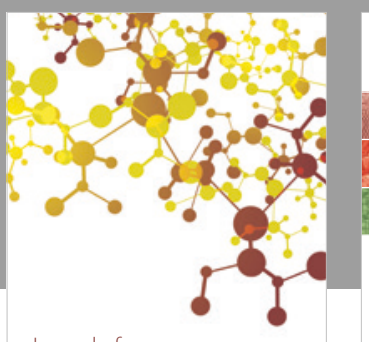

Journal of

Applied Chemistry
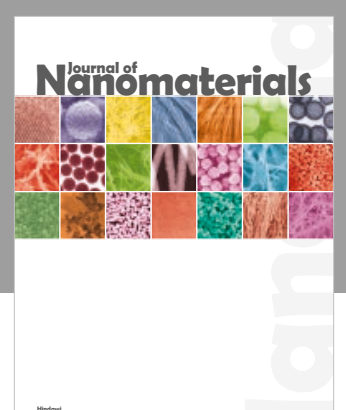

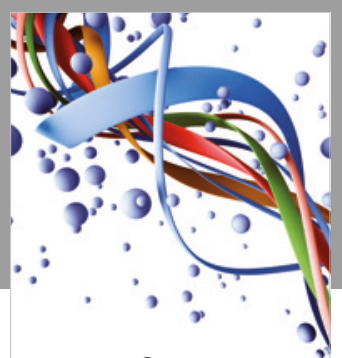

Scientifica

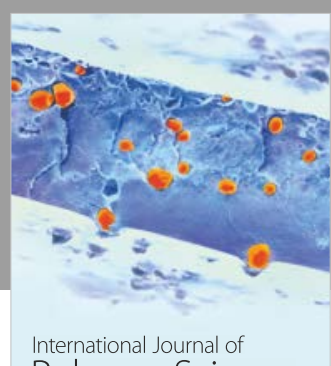

Polymer Science

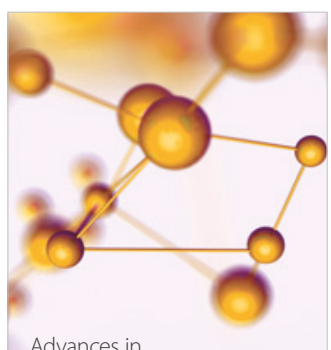

Physical Chemistry
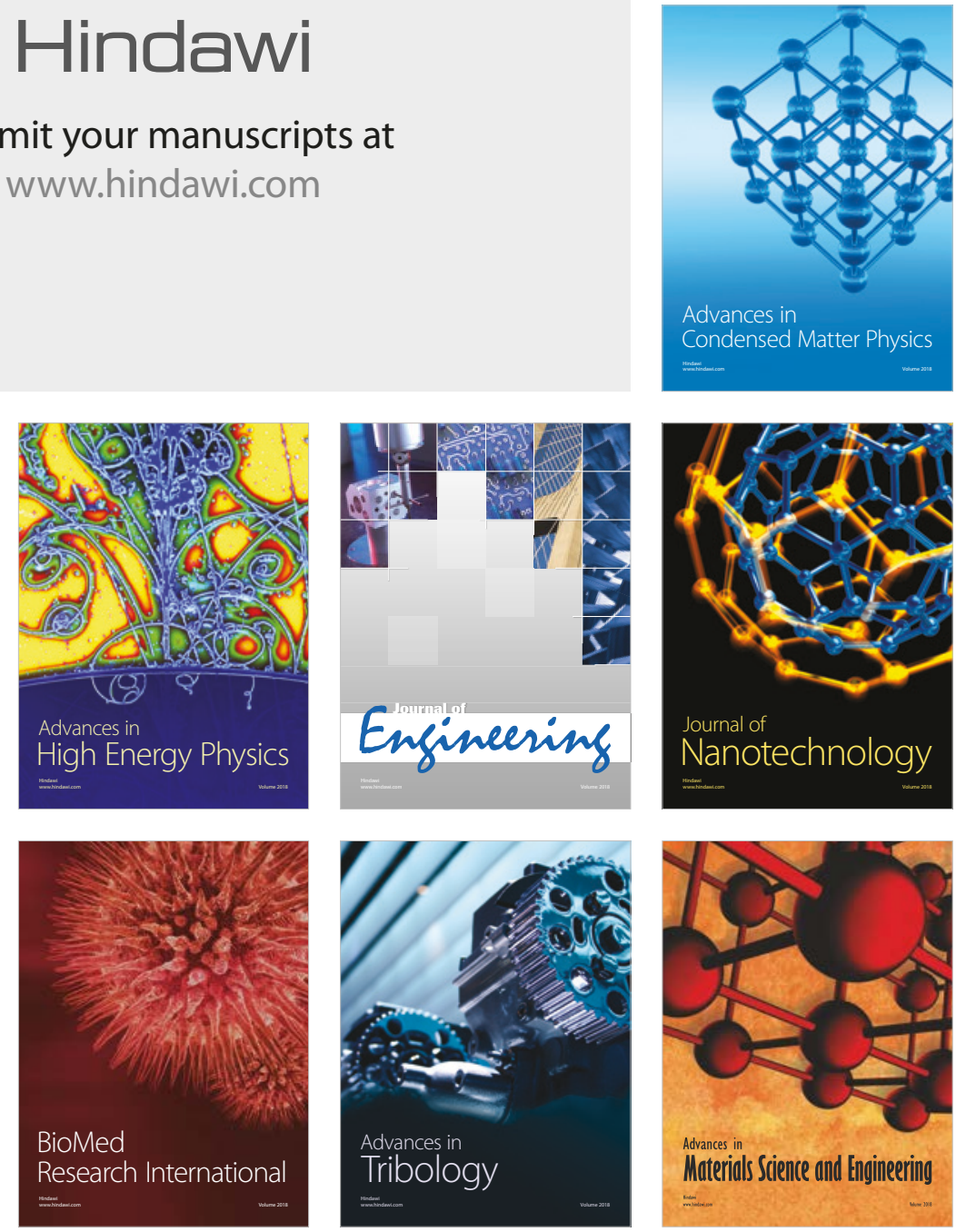